\title{
THEORETICAL RESEARCH OF COAL GASIFICATION PRODUCTS BURNING IN BOILERS AT TOMSK THERMAL POWER PLANT-3
}

\author{
A.A. Somov ${ }^{1}$, D.A. Mel'nikov ${ }^{1}$, D.V. Gvozdjakov², V.E. Gubin², Yu.S. Borovikov², A.S. Matveev²a \\ ${ }^{1}$ Open joint stock company «VTI», 115280 Moscow, Russia \\ ${ }^{2}$ National Research Tomsk Polytechnic University, 634050 Tomsk, Russia
}

\begin{abstract}
Mathematical modeling of primary fuel change into power gas in power generating boiler with productivity of steam 160 th was done. Research of aggregate work on some power modes was completed. Characteristic curves of efficiency coefficient at different loads and ratio on power and natural gases burning were made. Practicability of power gas use as fuel was proved.
\end{abstract}

\section{Statement of problem and its solution}

In the last few years employees of VTI together with TPU have been developing the first domestic steam and gas installation with intracycle gasification of solid fuel. One peculiarity of steam and gas installation with intracycle gasification of solid fuel simultaneous working is that feeding of gasifier with air is done from gas turbine compressor. The biggest part of blasting air energy turns into power gas compression energy and then into revolution work by means of its combustion products expansion in steam path of gas generator turbine. It should be noted that researches in this sphere have been included into Program of electric power development in Russia till 2020.

Design results of Russian power boiler used at Tomsk thermal power plat-3 with steam productivity $160 \mathrm{t} / \mathrm{h}$ at power gas burning are presented in the work.

Mathematical model of boiler was developed with the help of software package Boiler Designer (a product of OPTSIM-K and KED) and its verification on plant design data and process flow test were completed. The main condition of the mathematical model was full equality of heating surface parameters, input into the model, to real construction and geometrical heating surfaces. Correlations were made on all points of boiler where heat carrier flow parameters measurements on gas, air and steam water paths were made. Variable parameters able to change the character of heat exchange in design model and make its adjustment are:

-burning parameter;

- screen heat efficiency coefficient;

- coefficients of use and pollution of separate heating surfaces.

Use of the parameters allows changing surface heat absorption and gas and environment temperatures on entering the following heating surface. Values burning parameter, screen heat

a Corresponding author : matveev@tpu.ru

This is an Open Access article distributed under the terms of the Creative Commons Attribution License 4.0, which permits unrestricted use, distribution, and reproduction in any medium, provided the original work is properly cited. 


\section{MATEC Web of Conferences}

efficiency coefficient, coefficients of use and pollution of separate heating surfaces and are taken as standard at the first level of design.

Analysis of the received data illustrates a good matching of parameters on both steam water and air gas boiler paths. Small differences were due to the following conditions:

- $\quad$ the difference in design of heat absorption of evaporator platen;

- $\quad$ not correct modeling of crescent within plant design;

- $\quad$ simplified understanding of current environment behavior in overhead heating surface in plant design;

- $\quad$ not correct plant design of furnace irradiation absorption.

The above-described factors, in particular, destined a slightly bigger temperature of overheated steam past boiler (about $2^{\circ} \mathrm{C}$ ) and a slightly less steam productivity of boiler (about $0.7 \mathrm{t} / \mathrm{h}$ ) at given fuel rate on model data in comparison with plant design results.

The main parameters on paths and design schemes of gas and steam water paths are presented in fig. 1.

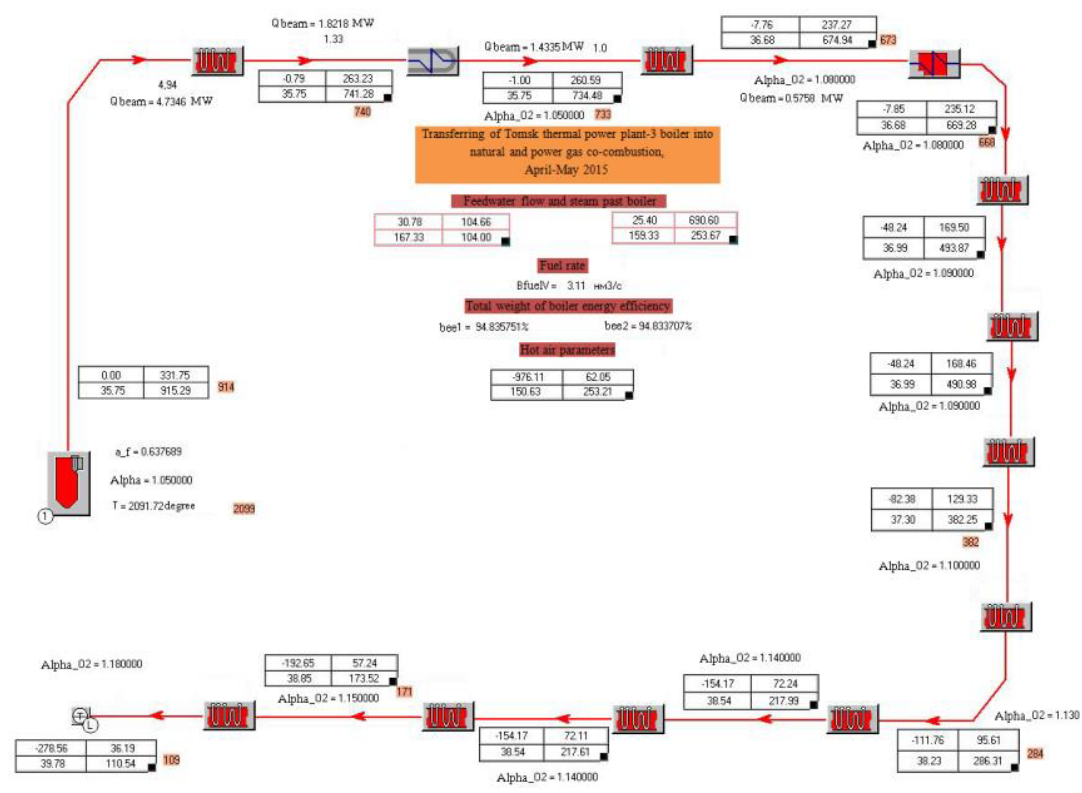

Figure 1. Design scheme of gas path

Research results done at developed and added mathematical model with an option imitating feeding in power gas furnace at $100 \%$ and $50 \%$ of nominal power are presented in table 1 .

Table 1. Research results

\begin{tabular}{|l|c|c|c|c|}
\hline \multicolumn{1}{|c|}{ Parameter } & \multicolumn{2}{c|}{ Power $100 \%$} & \multicolumn{2}{c|}{ Power $100 \%$} \\
\hline Share (on heat) of power gas, $\%$ & 20 & 100 & 40 & 100 \\
\hline Main steam rate, $\mathrm{t} / \mathrm{h}$ & 153.1 & 153.2 & 80.1 & 80.1 \\
\hline Main steam pressure, $\mathrm{kgs} / \mathrm{cm} 2$ & \multicolumn{2}{|c|}{25.4} & & 18.35 \\
\hline Main steam temperature, ${ }^{\circ} \mathrm{C}$ & 285 & 287 & 271 & 272 \\
\hline Feedwater flow, $\mathrm{t} / \mathrm{h}$ & 154.8 & 154.9 & 81.75 & 82.27 \\
\hline Steam temperature past boiler (after injection), ${ }^{\circ} \mathrm{C}$ & 285 & 287 & 271 & 272 \\
\hline Adiabatical burning temperature ${ }^{\circ} \mathrm{C}$ & 2016 & 1841 & 1917 & 1800 \\
\hline Furnace exit gas temperature, ${ }^{\circ} \mathrm{C}$ & 926 & 945 & 681 & 704 \\
\hline Exit-gas temperature, ${ }^{\circ} \mathrm{C}$ & 128 & 161 & 105 & 120 \\
\hline $\begin{array}{l}\text { Excess air factor in combustion products past } \\
\text { furnace }\end{array}$ & \multicolumn{2}{|c|}{1.02} & 1.02 & \multirow{2}{*}{1.02} \\
\hline
\end{tabular}




\begin{tabular}{|l|c|c|c|c|}
\hline \multicolumn{1}{|c|}{ Parameter } & \multicolumn{2}{c|}{ Power $100 \%$} & \multicolumn{2}{c|}{ Power $100 \%$} \\
\hline Excess air factor in combustion products past boiler & \multicolumn{2}{|c|}{1.13} & 1.13 & 1.13 \\
\hline Power gas rate, $\mathrm{nm} 3 / \mathrm{h}$ & 5.42 & 24.36 & 5.42 & 12.42 \\
\hline Natural gas rate, $\mathrm{nm} 3 / \mathrm{m}$ & 2.52 & 0 & 0.94 & 0 \\
\hline Total weight of boiler energy efficiency, \% & 93.73 & 91.32 & 94.72 & 93.46 \\
\hline
\end{tabular}

On the basis of the received data characteristic curves of boiler efficiency coefficient at different loads and ratio on power and natural gas burning was made (fig. 2).

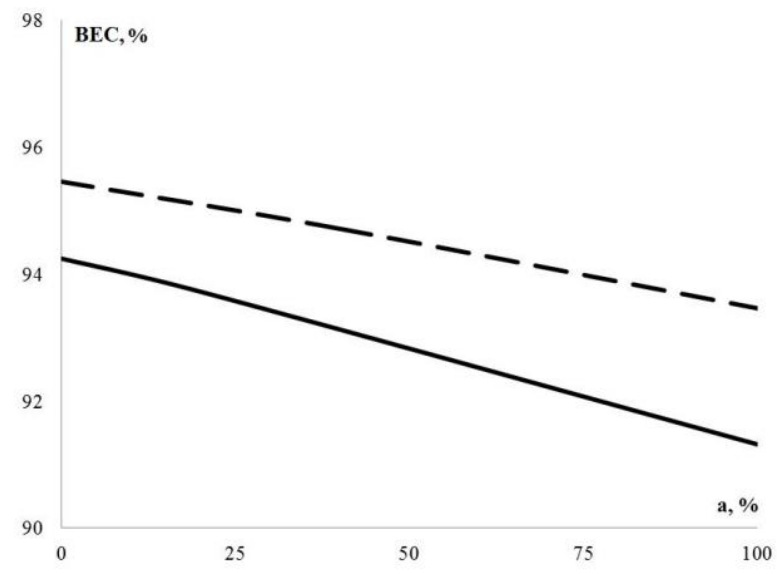

Figure 2. Boiler efficiency coefficient from a share of power gas - at 50\% (broken line); - $100 \%$ (full line) load

The research of power generating boiler at nominal and 50\% load at partial and full change of primary fuel into power gas was done. It was stated that design target values maintenance in these ranges is possible and does not need activities on reconstruction of heating surfaces and change of boiler heating scheme. The main expenses from utilization of low calories fuel are connected with vapor formation on hot end of economizer, and a small decrease of boiler efficiency coefficient in technical and economic change. Practicability of power gas use as fuel for change of natural gas can be set at economic design of gasification installation exploitation costs.

The work has been done in FCAEI HE and open joint stock company 'VTI' in framework of federal focused program implementation "Research and Development on Priority Orientation of Science and Technology Complex Development in Russia 2014-2020”, unique identifier 'Applied Research and Experimental Developments'RFMEFI58114X0001.

\section{References}

1. G.G. Ol'hovskij, SI. Suchkov, P.A. Berezinec, Heat engineering, 2, 2 (2010)

2. D.D. Sulimov, Heat engineering, 2, 27 (2010).

3. Technical report on the operational tests and commissioning of steam boiler equipment such as E-160-2.4-250 BT Art. №4, Tomsk 5 GEC-3 Ghazawi fuel on 30.08.2012 